\title{
THE EFFECT OF SELECTION ON ASCOSPORE SIZE IN NEUROSPORA CRASSA
}

\author{
J. A. PATEMAN \\ Department of Genetics, University of Sheffield*
}

Received 18.iii. $5^{8}$

\section{INTRODUCTION}

THE heterothallic fungus Neurospora crassa develops, under appropriate conditions, asci each of which contains eight ascospores in a linear array. When isolated from the wild and maintained under the usual laboratory conditions, the number of mature ascospores per ascus is always eight and the size of the normal ascospores varies very little. However, large ascospores, which are approximately twice the normal size, occasionally occur. Their frequency is less than one in ten thousand. Cultures from a number of these large ascospores were used as the starting point in an experiment in which selection was exercised for large ascospore size. The results of the selection experiment and of other studies on the inheritance of ascospore size in Neurospora crassa are reported in this paper.

\section{METHODS}

The strains used have complicated pedigrees but all, with the possible exception of the St Lawrence wild-type, were derived originally from the Abbot and/or the Lindegren wild-types. The wild-type, St Lawrence $A$ (StL. $A$ ), which was obtained from Dr D. Newmeyer, is probably also derived to a large extent from the Abbot and Lindegren wild-types.

The vegetative cultures were maintained on agar slopes of Fries No. 3 (Beadle and Tatum, I945) medium. All crosses were made on agar slopes of a medium favouring sexual reproduction (Westergaard and Mitchell, 1947) and incubated at $25^{\circ} \mathrm{C}$.

The ascospores were measured with a micrometer eyepiece and the unit of measurement is approximately $2 \cdot 17 \mu$.

\section{SELECTION FOR INCREASED ASCOSPORE SIZE}

(i) Method of selection

A particular cross between two apparently normal strains made in this laboratory produced an abnormally high frequency, approximately 3.4 per cent. of large (giant) ascospores. Four of these large ascospores germinated and gave good cultures and two fertile crosses were obtained from intercrosses between them. The frequency of large ascospores increased significantly (to about II.4 per cent.) in

* Present address : Department of Botany, University of Melbourne, Australia. 
these crosses, and it was therefore decided to begin a simple selection experiment.

The following procedure was adopted. All crosses were between cultures derived from large ascospores. From each of the two crosses mentioned above, in which all four parents were dissimilar, four or five cultures from large ascospores were obtained. From intercrosses between these cultures, two crosses, in which all four parents were dissimilar, were used to obtain the next generation of cultures.

The essential features of this scheme are that only cultures derived from phenotypically-large ascospores (mean length c. I9) are used as parents for the next generation, and that four different strains are used in each set of parental crosses. This mating procedure was used throughout most of the experiment, but on three occasions, the seventh, twelfth and thirteenth generations of selection, progeny from a single cross had to be used to carry on the line.

\begin{tabular}{|ccc|ccc|}
\hline Crosses & & Ist generation & Crosses & & 2nd generation \\
\cline { 1 - 2 } $1 \times 2$ & $\rightarrow$ & 5 and 6 & $5 \times 7$ & $\rightarrow$ & 9 and 10 \\
$3 \times 4$ & $\rightarrow$ & 7 and 8 & $6 \times 8$ & $\rightarrow$ & 11 and 12 \\
\hline
\end{tabular}

TEXT-FIG. 1.-Mating procedure in selection experiment for large ascospore size.

The response to selection was at first followed by classifying samples of ascospores from each generation into large (giant) and normalsized ascospores. The samples of ascospores were taken from at least two, and usually three or four different crosses, in each generation. The total number of ascospores classified was at least 500 in each generation. The result of selection during the first eight generations, based on the frequency counts of large and normal-sized ascospores, has been published previously (Pateman, i 955).

\section{(ii) Response to selection}

It was realised after the experiment had continued for a number of generations that the response to selection for increased ascospore size was a complex phenomenon. The main factors in this response were as follows : (a) A number of asci containing four large ascospores instead of the usual eight normal ascospores were observed. At first the four-spored asci were rare and only one or two of the spores matured in each ascus. But, by the eighth and succeeding generations, there was one ascus containing four large, apparently mature, ascospores per two or three perithecia.

(b) During the first generations, the majority of the asci contained eight normal, mature, ascospores. By the eighth and succeeding generations, asci with eight mature ascospores were very rare. After the sixth-eighth generations, only one or two of the ascospores matured 
in the great majority of those asci in which eight ascospores were delimited.

(c) There was a general increase in ascospore size which resulted in an increasing number of ascospores intermediate between normal and large, and also in the appearance of rare, very large ascospores.

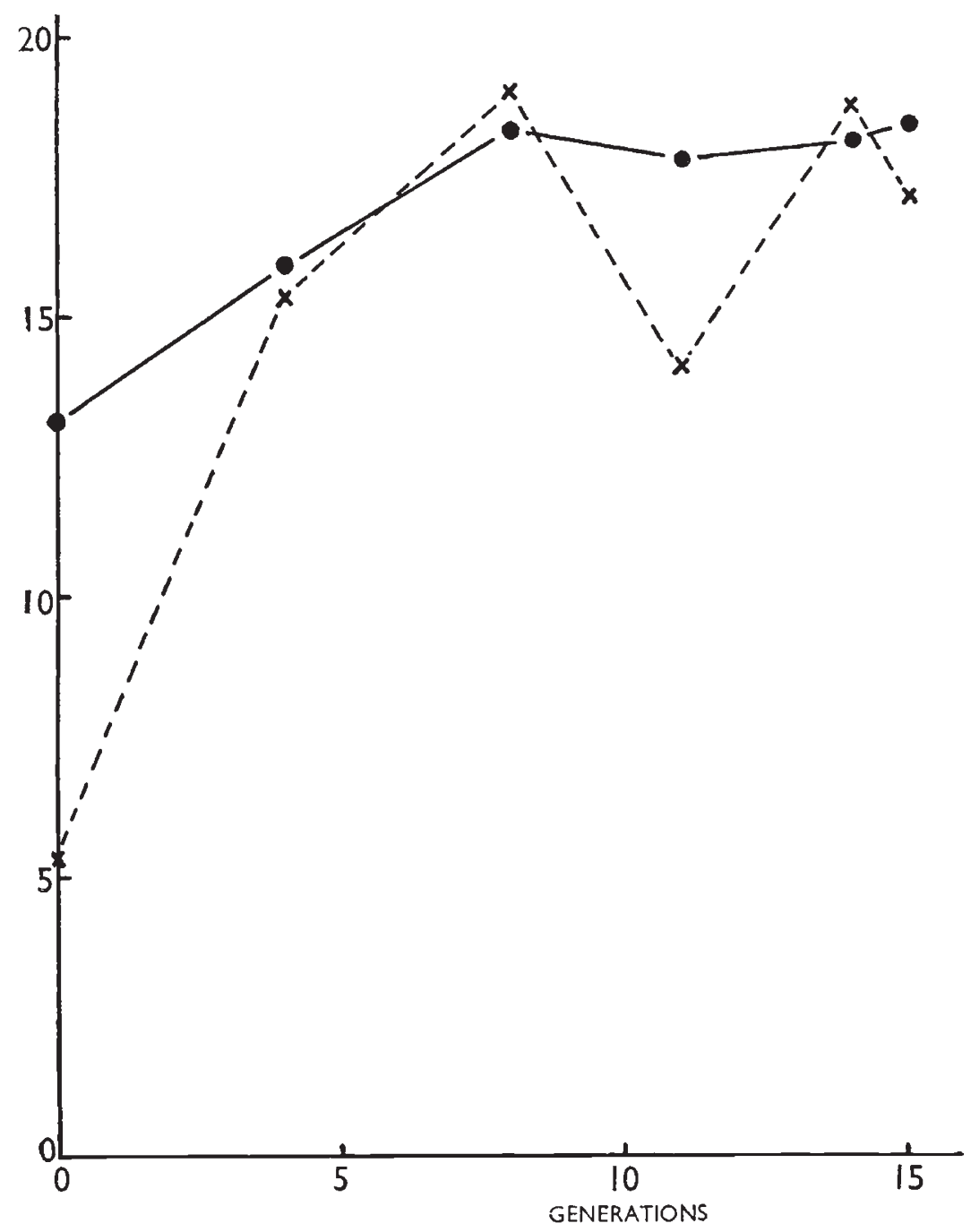

ASCOSPORE LENGTH (SOLID LINE) AND COEFFICIENT OF VARIATION (DOTTED LINE)

TEXT-FIG. 2.-The effect of selection for increased ascospore size, together with the corresponding coefficients of variation.

(d) As selection proceeded, there was a great increase in the number of asci which aborted at all stages of development, up to that at which ascospores were "cut out" in the ascus but did not mature. In fact, by the eighth generation only about 20 per cent. of the asci contained any mature ascospores at all. The plate illustrates some of the features described in $(a)$ to $(d)$. 
Since selection resulted in the appearance of a new type of ascus in addition to a general increase in size, it was thought desirable to measure individually samples of ascospores and to count the frequencies of four-spored and eight-spored asci. The total number of asci in which half or more of the ascospores were mature was very small.

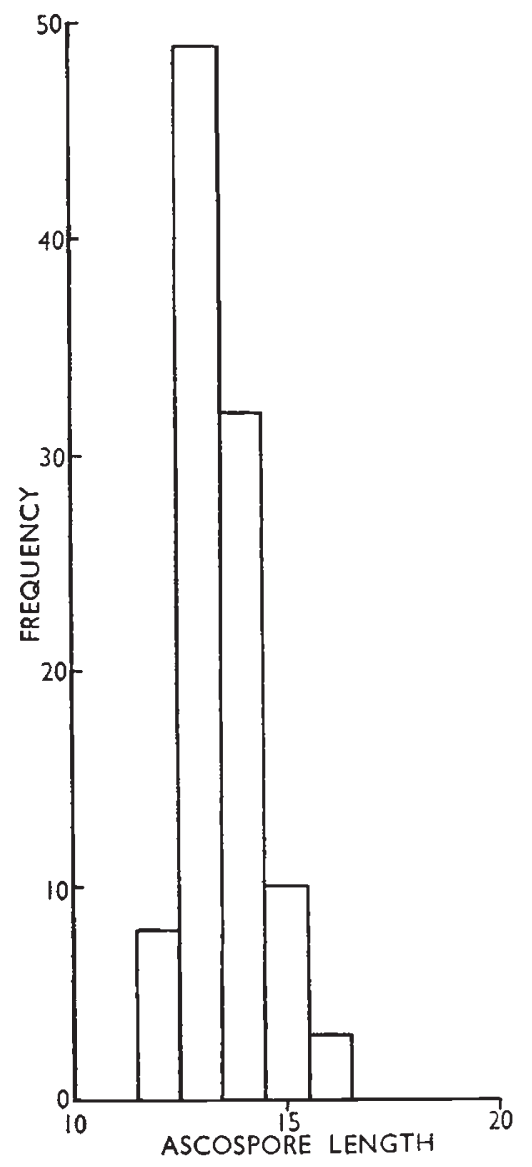

Text-Fig. 3.-The frequency histogram of the lengths of a sample of 100 ascospores from a cross between the two stock wild-types, StL. $A$ and I $96 a$. Also, the asci were very fragile and many were broken and rendered unclassifiable by the operation of opening the perithecium. This fragility of the asci varied unpredictably from cross to cross, and the collection of the required data was therefore impracticable. However, samples of roo ascospores from various generations were measured and some of these results are shown in text-fig. 2. Both the maximum length and breadth of each ascospore were measured, the mean length increased by about 35 per cent., the breadth by about 20 per cent., but only the change in mean ascospore length will be dealt with in this paper. It can be seen from text-fig. 2 that selection resulted in an increase of mean ascospore length from I 3 -I 4 to $17 \cdot 5$ I8.5. The range of about I unit covers the variation usually found between different crosses of the same generation. After the eighth generation there was no further significant change in mean ascospore length. In text-fig. 2, the values of the coefficient of variation $(\mathrm{C}=$ (standard deviation of $x$ ) $/ \bar{x}$, expressed as a percentage) are plotted, together with the corresponding means.

It can be seen that the coefficient of variation increases from a value of about 5 per cent. for normal crosses to values of I $^{-1} 8$ per cent. after selection for increased ascospore size. This threefold increase in the coefficient of variation, together with the fact that the majority of asci abort at some stage of development and produce few or no viable ascospores, indicates that selection for large ascospores has produced a marked instability of ascus development.

Text-figs. 3-7 show the frequencies of the various size classes in samples of Ioo ascospores. It can be seen from text-fig. 3, which is 
SELECTION FOR ASCOSPORE SIZE

5

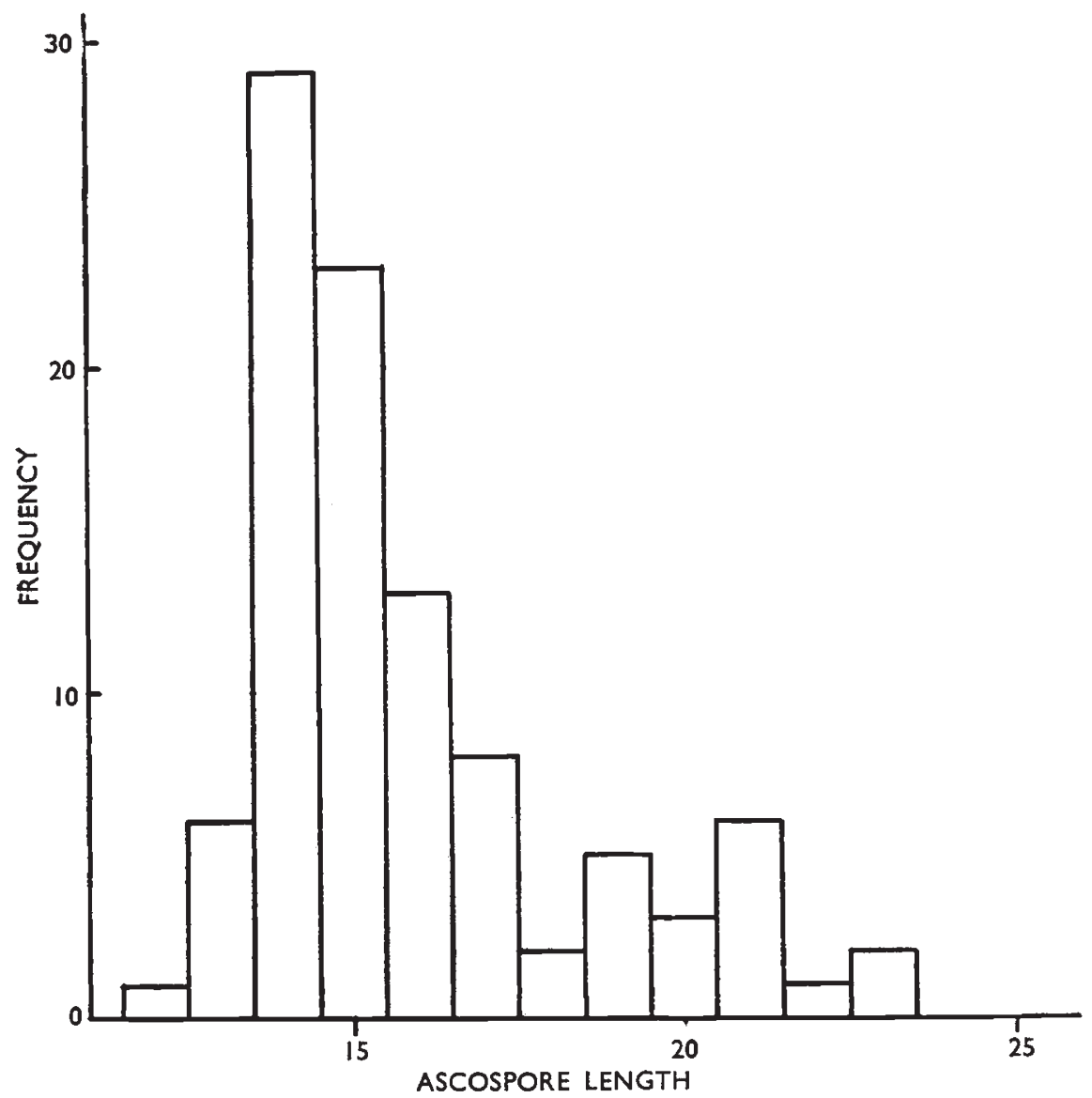

TEXT-FIG. 4. -The frequency histogram of the lengths of a sample of yo ascospores from a cross between two large-spored strains from the fourth generation of selection.

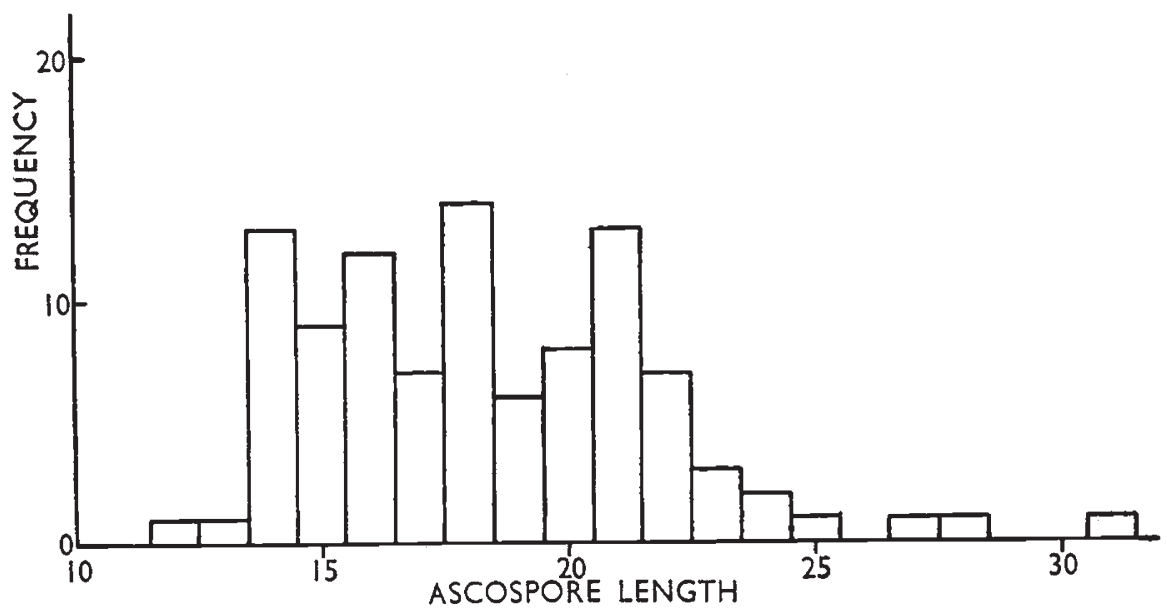

TEXT-FIG. 5. -The frequency histogram of the lengths of a sample of 100 ascospores from a cross between two large-spored strains from the eighth generation of selection.

A 2 
typical of wild-type crosses, that there is not a great deal of variation about the mean of 13.55 , in fact, some 80 per cent. of the ascospores fall into the range $12 \cdot 5-14 \cdot 5$. Text-fig. 4 is the histogram of the measurements of a sample of ascospores taken from a cross between

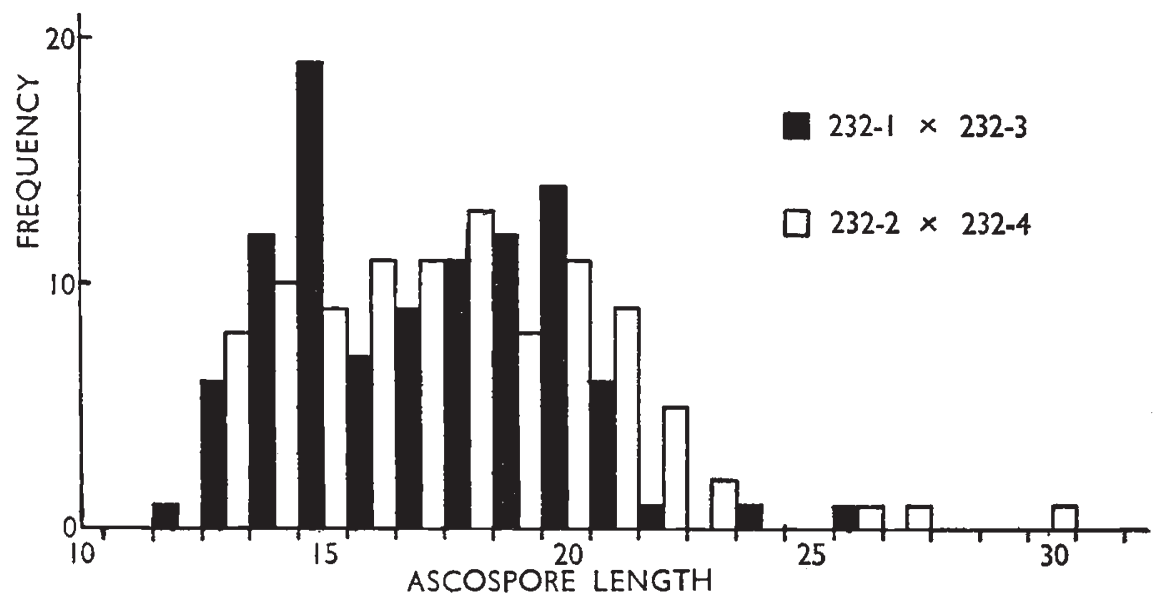

TEXT-FIG. 6.-The frequency histograms of the lengths of samples of $\mathrm{I}$ oo ascospores from two different crosses between large-spored strains. The four-spored ascus 232 was obtained from a cross between two large-spored strains from the sixteenth generation of selection. The mean ascospore lengths of the two crosses are given in table 5 .

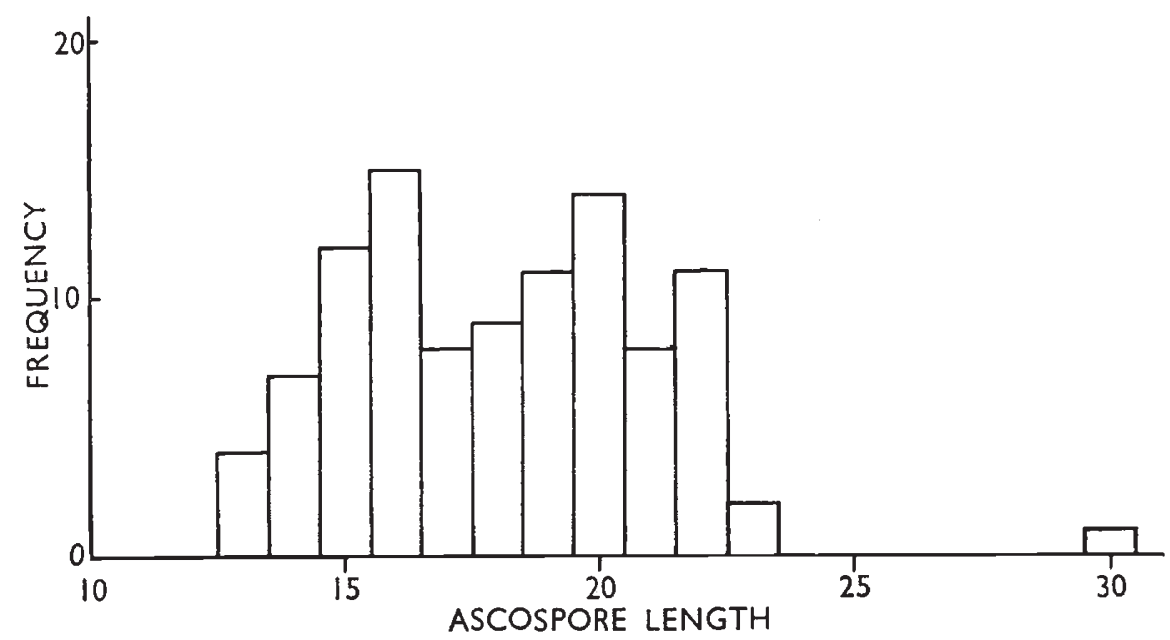

TEXT-FIG. 7.-The frequency histogram of the lengths of a sample of roo ascospores from a cross $(234-1 \times 234-7)$ between two normal-spored strains from the sixteenth generation of selection.

two large ascospores obtained after four generations of selection. There is a definite suggestion of bimodality with a peak at I 4 and another at about 20. It seems quite clear that the peak at about 20 is due to the proportion of asci which now cut out four large, instead of eight normal ascospores. In addition, there has been an increase in the mean length 
of the "normal" ascospores of about I unit, with the frequency of the $12 \cdot 5^{-1} 3.5$ class changing from 49 per cent. in fig. 3 to 6 per cent. in fig. 4. This is a clear indication that selection is having an effect over the whole range of ascospore size and is not just increasing the frequency of asci with four large spores. Text-fig. 5 is the histogram of the measurements of a sample of roo ascospores, taken from a cross between two large ascospores obtained after eight generations of selection. The obvious bimodality of text-fig. 4 is no longer apparent, all the classes in the range $13 \cdot 5-21 \cdot 5$ being more or less equally frequent.

\section{TABLE I}

Size of ascospores in two eight-spored and two four-spored asci from crosses between strains obtained after sixteen generations of selection. Asci 233 and 234 were both obtained from the same perithecium.

\begin{tabular}{|c|c|c|c|c|c|c|c|}
\hline \multirow{2}{*}{ Ascus } & \multirow{2}{*}{$\begin{array}{c}\text { Spore } \\
\text { number }\end{array}$} & \multicolumn{2}{|c|}{ Spore size } & \multirow{2}{*}{ Ascus } & \multirow{2}{*}{$\begin{array}{c}\text { Spore } \\
\text { number }\end{array}$} & \multicolumn{2}{|c|}{ Spore size } \\
\hline & & Length & Breadth & & & Length & Breadth \\
\hline 231 & $\begin{array}{l}1 \\
2 \\
3 \\
4 \\
5 \\
6 \\
7 \\
8\end{array}$ & $\begin{array}{l}\text { I } 5 \\
\text { I } 6 \\
\text { I } 5 \\
\text { I } 4 \\
\text { I } 5 \\
\text { I } 3 \\
\text { I } 4 \\
\text { I } 3\end{array}$ & $\begin{array}{l}7 \\
8 \\
8 \\
7 \\
7 \\
7 \\
8 \\
7\end{array}$ & 234 & $\begin{array}{l}\mathrm{I} \\
2 \\
3 \\
4 \\
5 \\
6 \\
7 \\
8\end{array}$ & $\begin{array}{l}\text { I } 4 \\
\text { I } 5 \\
\text { I } 3 \\
\text { I } 4 \\
\ldots \\
14 \\
16 \\
\text { I } 5\end{array}$ & $\begin{array}{c}7 \\
7 \\
7 \\
7 \\
\ldots * \\
6 \\
7 \\
6\end{array}$ \\
\hline 232 & $\begin{array}{l}\text { I } \\
2 \\
3 \\
4\end{array}$ & $\begin{array}{l}20 \\
\text { I } 9 \\
2 \mathrm{I} \\
19\end{array}$ & $\begin{array}{l}8 \\
9 \\
9 \\
8\end{array}$ & 233 & $\begin{array}{l}\text { I } \\
2 \\
3 \\
4\end{array}$ & $\begin{array}{l}19 \\
22 \\
20 \\
21\end{array}$ & $\begin{array}{l}7 \\
8 \\
9 \\
8\end{array}$ \\
\hline
\end{tabular}

* Ascospore did not mature.

The text-figs. 6 and 7 are histograms of the measurements from samples of one hundred ascospores obtained from two different crosses between strains from the sixteenth generation of selection. They show no significant difference from the eighth generation crosses. There was a rapid response for about the first eight generations. Thereafter the selection practised was apparently unable to produce further increase in mean ascospore length.

It is plausible to suggest that there are two populations of ascospores, one derived from four-spored asci the other derived from eight-spored asci, but the size distribution of each now overlaps the other to a considerable extent with the elimination of an intermediate trough in the histogram. This hypothesis is supported by the fact that the great majority of asci which have been observed contained either four or eight ascospores.

In table I measurements are given of the ascospores in typical eight-spored and four-spored asci from crosses between strains from the sixteenth generation of selection. It can be seen that there were 
at least two ascospores 15 units long and one 16 units long in each of the eight-spored asci : reference to text-fig. 3 shows that there has been an increase in the frequency of rather larger than " normal " ascospores compared with a cross between two unselected strains. Table 2 lists the ascospore measurements of a number of asci which were unusual with respect to the number or range of size of ascospores which they contained. The asci 235 and 236 were obtained from the backcross to the large ascospore parent of a member of the $F_{1}$ progeny of a cross between a wild-type and a sixteenth generation large ascospore (see

TABLE 2

Size of ascospores in various unusual types of asci

\begin{tabular}{|c|c|c|c|c|c|c|c|c|c|c|c|}
\hline \multirow{2}{*}{ Ascus } & \multirow{2}{*}{$\begin{array}{l}\text { Spore } \\
\text { no. }\end{array}$} & \multicolumn{2}{|c|}{ Spore size } & \multirow{2}{*}{ Ascus } & \multirow{2}{*}{$\begin{array}{c}\text { Spore } \\
\text { no. }\end{array}$} & \multicolumn{2}{|c|}{ Spore size } & \multirow{2}{*}{ Ascus } & \multirow{2}{*}{$\begin{array}{c}\text { Spore } \\
\text { no. }\end{array}$} & \multicolumn{2}{|c|}{ Spore size } \\
\hline & & Length & Breadth & & & Length & Breadth & & & Length & Breadth \\
\hline 228 & $\begin{array}{l}\mathrm{I} \\
2 \\
3 \\
4 \\
5 \\
6 \\
7 \\
8\end{array}$ & $\begin{array}{l}16 \\
17 \\
17 \\
16 \\
17 \\
17 \\
17 \\
16\end{array}$ & $\begin{array}{l}7 \\
8 \\
8 \\
8 \\
8 \\
7 \\
7 \\
8\end{array}$ & 237 & $\begin{array}{l}\text { I } \\
2 \\
3 \\
4 \\
5 \\
6 \\
7 \\
8\end{array}$ & $\begin{array}{l}\cdots \\
\text { I4 } \\
\text { I5 } \\
14 \\
15 \\
13 \\
15 \\
19\end{array}$ & $\begin{array}{c}\ldots * \\
7 \\
7 \\
7 \\
8 \\
8 \\
7 \\
8\end{array}$ & 235 & $\begin{array}{l}\text { I } \\
2 \\
3 \\
4 \\
5 \\
6 \\
7 \\
8\end{array}$ & $\begin{array}{l}\text { I1 } \\
\text { I } \\
\text { 12 } \\
\text { I } \\
\text { 12 } \\
\text { 12 } \\
15 \\
16\end{array}$ & $\begin{array}{l}6 \\
5 \\
6 \\
6 \\
6 \\
6 \\
7 \\
6\end{array}$ \\
\hline $23^{6}$ & $\begin{array}{l}\text { I } \\
2 \\
3 \\
4 \\
5\end{array}$ & $\begin{array}{l}16 \\
16 \\
\mathrm{I} 5 \\
\mathrm{I} 2 \\
\mathrm{I} 3\end{array}$ & $\begin{array}{l}8 \\
8 \\
8 \\
7 \\
7\end{array}$ & 230 & $\begin{array}{l}\text { I } \\
2 \\
3 \\
4 \\
\cdots\end{array}$ & $\begin{array}{l}22 \\
22 \\
21 \\
23 \\
\cdots\end{array}$ & $\begin{array}{l}\text { I I } \\
\text { IO } \\
\text { IO } \\
\text { I I } \\
\ldots\end{array}$ & $229\}$ & $\begin{array}{c}\mathbf{I} \\
\ldots \\
2 \\
3 \\
\cdots\end{array}$ & $\begin{array}{l}40 \\
\cdots \\
23 \\
2 \mathrm{I} \\
\cdots\end{array}$ & $\begin{array}{r}9 \\
\cdots \\
9 \\
9 \\
\cdots\end{array}$ \\
\hline
\end{tabular}

* Ascospore did not mature.

later section). All the other asci in table 2 were from crosses between large ascospore strains obtained from the sixteenth generation of selection.

\section{(iii) Self-fertile strains}

Out of a total of nine large ascospores which germinated and formed the third generation of selected ascospores, two ascospores were observed to grow slowly for about the first two days after germination, then they grew faster and formed healthy vegetative cultures. One of these cultures later developed a few scattered perithecia which produced mature ascospores. In the fourth generation two out of ten large ascospores which germinated were initially slow growing and developed into self-fertile cultures. Another initially slow-growing, self-fertile, large ascospore strain was obtained in each of the fifth and sixth generations of selection. In all, five large ascospores which were initially slow growing and self-fertile and four large ascospores which were initially slow growing, but not self-fertile, were obtained between the third and sixth generations of selection. A total of twenty-five: 
large ascospores from the self-fertile strains were cultured, fifteen of them were initially slow growing, but none were self-fertile. Nothing further was done with these strains, since it was expected that as selection for larger ascospore size continued, the frequency of selffertile strains would increase and the nature of these strains could be investigated in more detail later. In fact, no more self-fertile or initially slow-growing strains were obtained from the sixth to the sixteenth generation of selection.

It may be that the phenomenon of slow initial growth immediately after germination was unconnected with the self-fertility of certain strains. But there is a possible explanation which suggests there may have been a connection. It is known to be difficult to obtain heterocaryons in Neurospora crassa which carry both mating-type alleles (Garnjobst and Wilson, I 956). Thus if an ascospore was formed which was either heterocaryotic or heterozygous for the mating-type alleles, this might result in uncertain, slow growth immediately after germination. Only in a minority of cases might a strain be able to overcome this initial unbalance and develop normally while still carrying both mating-type alleles and thus become a self-fertile strain. In the majority of instances normal development may occur as the result of the elimination of one or other of the mating-type alleles and a resultant homothallic strain. This would explain why all five selffertile strains were initially slow growing, but many initially slowgrowing strains were not self-fertile.

Why the two phenomena, whether connected or not, should have been so transitory is unknown; it may be that certain rare genes were necessary to produce the effects and at least one of these was eliminated by chance in the process of selection, since the mating population was small.

\section{4. $F_{1}$ AND BACKCROSSES FROM LARGE-SPORED STRAINS CROSSED TO WILD-TYPE}

The results obtained from crossing large-spored strains from both the third and fifth generations of selection to wild-types and the frequency of large ascospores in the progeny from $F_{1}$ crosses have been published previously (Pateman, I955).

Samples of twenty to Ioo ascospores from the $F_{1}$ progeny of each of sixty crosses between strains from the fifteenth and sixteenth generations of selection and wild-type have been measured. The mean lengths of the samples of ascospores from these crosses were all within the range $12.8-13.92$, the mean length of a sample of roo ascospores from a typical wild-type cross (see text-fig. 3 ) was 13.55 . It is evident that there is no significant difference between the mean ascospore length of the $F_{1}$ and the wild-type crosses. Thus the wild genotype shows complete dominance in crosses with genotypes built up by fifteen or sixteen generations of selection for large ascospore size. 
Since the wild genotype showed such complete dominance, it was considered that segregation of nuclear factors affecting type of ascus and ascospore size might be more effectively demonstrated in backcrosses to the large-spored parent than in crosses between different $\mathrm{F}_{1}$ strains. Accordingly fifty single ascospore strains were isolated from a cross between 233-4 and the StL. $A$ wild-type. The ascospore from which 233-4 developed measured 2I $\times 8$ (see table I). All the $F_{1}$ ascospores were of normal size. The fifty $F_{1}$ strains were backcrossed

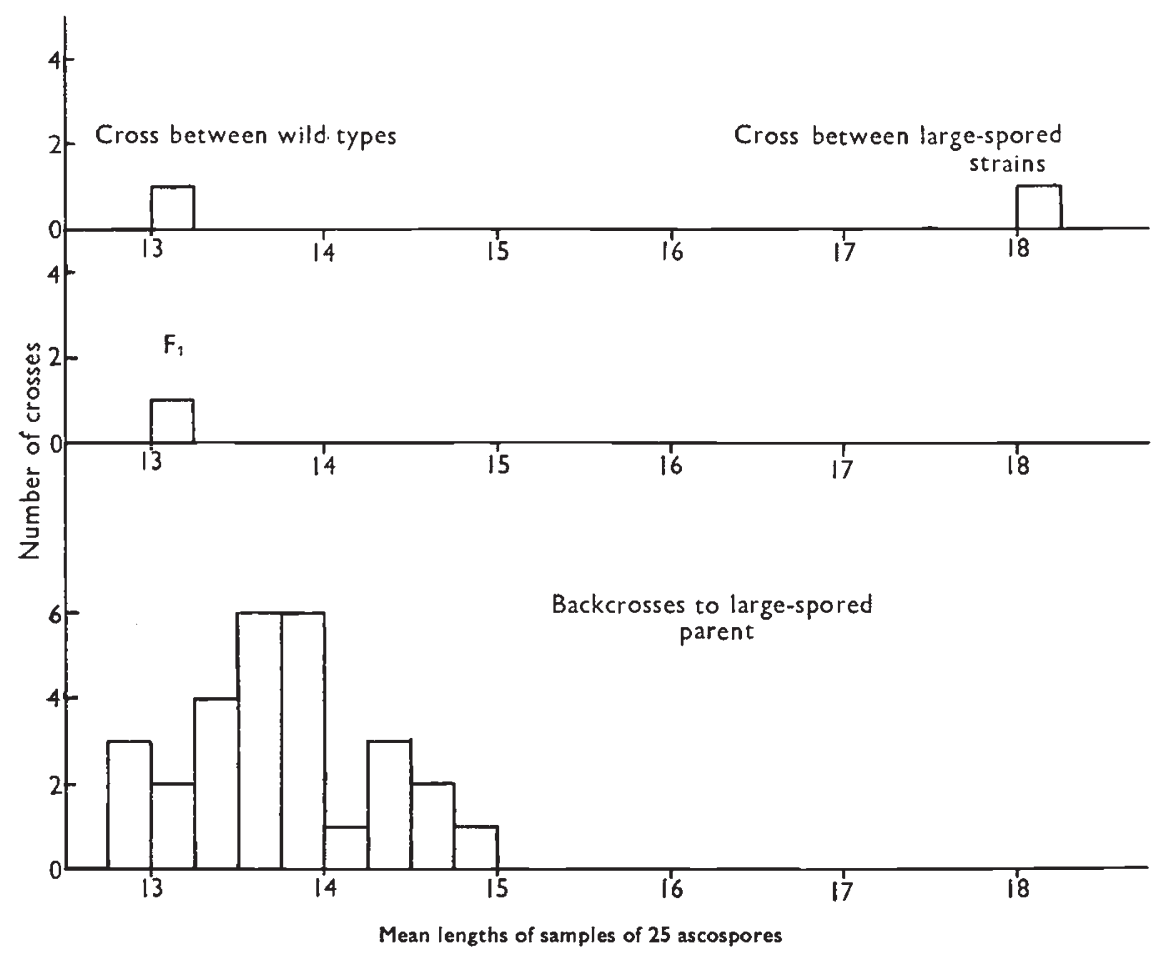

TeXT-Fig. 8.-A comparison of the mean ascospore lengths from wild-type crosses, from crosses between large-spored strains, from an $F_{1}$ cross, and from backcrosses to the largespored parent. The $F_{1}$ cross is identical with wild-type crosses. There is a range of intermediate values amongst the twenty-eight different backcrosses.

to 233-4 and a total of twenty-eight fertile backcrosses was obtained. A sample of twenty-five ascospores from each of these backcrosses was measured. The mean length of the ascospores in each of these samples was grouped into class ranges of 0.25 units and text-fig. 8 is a histogram which shows the frequency of the different classes in the total of twenty-eight crosses.

It also shows, for comparison, the mean length of ascospores from crosses of the parental strains to wild-type and to large-spored strains respectively, and the mean length of the $F_{1}$ ascospores. The difference between the means of any two samples of ascospores in adjacent classes is statistically significant at about the $0^{0-005}$ level. The 
difference between the means of any two samples of ascospores, in different and other than adjacent classes, is significant at less than the oo I level. It seems reasonable to suggest that segregation of polygenes occurred during the formation of the $F_{1}$ ascospores and that this segregation resulted in the wide range of mean ascospore lengths in the twenty-eight backcrosses to the large-spored parent.

In fig. 9 are two histograms. One consists of the measurements of a sample of 100 ascospores with a mean of I3.II from the cross $233-4 \times \mathrm{StL}$. $A$. The other consists of the measurements of a sample of roo ascospores from the backcross of an $F_{1}$ strain, i235, with strain 233-4. This sample has a mean length of 14.72. This illustrates how the genotype of the phenotypically normal, $\mathrm{F}_{1}$ ascospore, when crossed to that of the large-spored strain 223-4, resulted in a distinctly different distribution of ascospore sizes in the progeny to that found in the $\mathrm{F}_{1}$ ascospores or in the progeny of wildtype $\times$ wild-type crosses. Also, a four-spored ascus, a five-spored ascus and a typical eight-spored ascus, all from the backcross of an $F_{1}$ strain, I 238, to the large-spored parent 223-4 are illustrated in the plate figs. 4-6. This again suggests that segregation of polygenes affecting ascospore size and ascus type occurred during meiosis in the parental cross.

\section{APPARENT SEGREGATION OF POLYGENES IN FOUR- SPORED AND EIGHT-SPORED ASCI}

One complete eight-spored ascus, numbered 234, and two complete four-spored asci, numbered $23^{2}$ and 233, were obtained from a cross between two large-spored strains from the fifteenth generation of selection. The sizes of the ascospores in these asci are given in table $I$. The four-spored ascus 233 and the eight-spored ascus 234 were both obtained from the same perithecium. The four possible crosses between members of the same ascus $23^{2}$ and the four possible crosses between members of the ascus 233 were set up. Also, all the possible crosses between the member strains of ascus 234 were set up. Samples of 100 ascospores from each of these crosses were measured. There were apparently significant differences in the mean length of ascospores from various crosses between members of the same ascus. It was considered that these differences might be the result of segregation of polygenes during meiosis.

In order to confirm this apparent segregation of polygenes during the formation of the asci, the following experiments were carried out. The four possible crosses between the four strains of ascus 232 were set up with five replicates of each type of cross. All the crosses were set up at the same time, on crossing slopes made from the same batch of medium and were kept close together in the culture room. These precautions were taken in order to minimise the between-replicate variation due to environmental differences. A sample of twenty ascospores from each of the twenty crosses was measured, the mean 


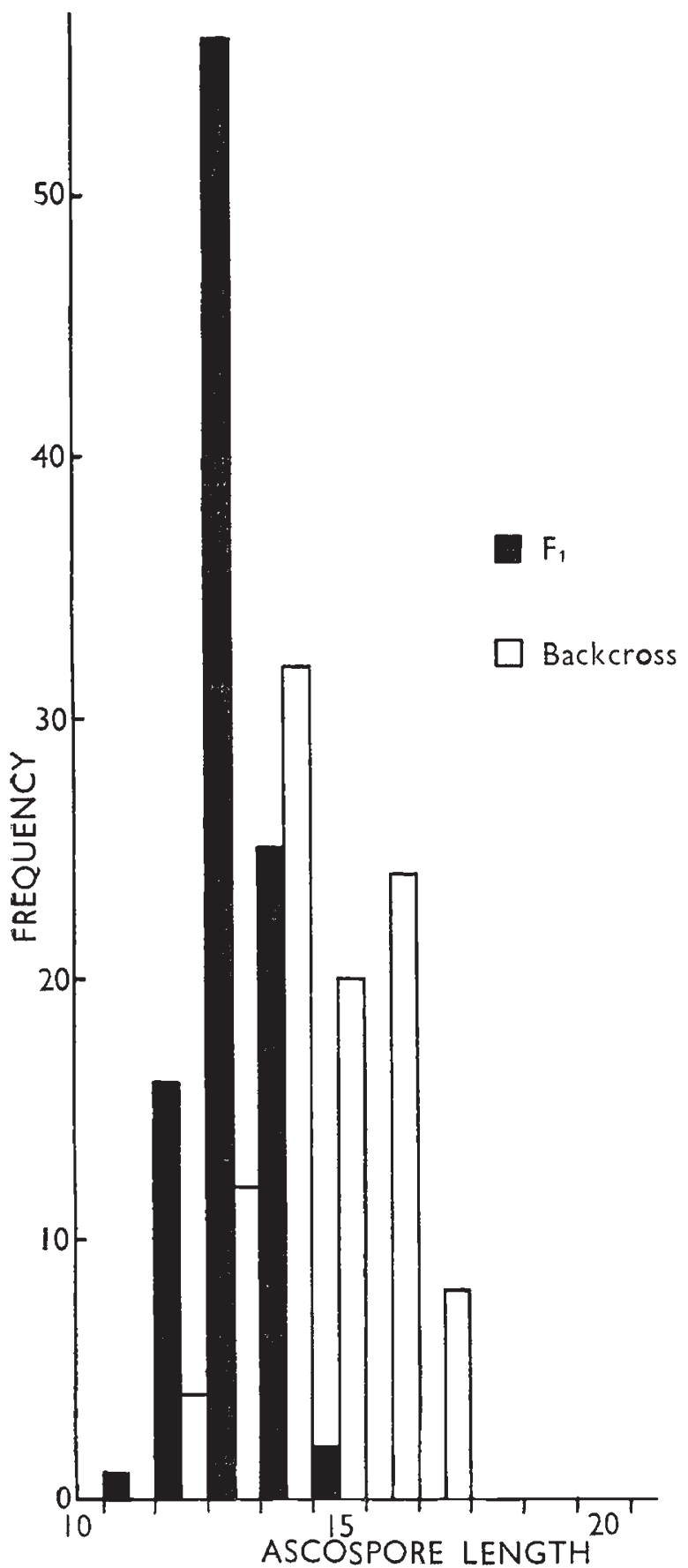

Text-FIG. 9.-The frequency histograms of samples of 100 ascospores from an $F_{1}$ and from a backcross to the large-spored parent. 
length of each of these samples is given in table 3. The analysis of variance of these results is given in table 4. The mean square (MS = 9.593) for the comparison between the four different types of cross is less than the mean square for comparison of replicate crosses $(\mathrm{MS}=$ I7.255). The sum of squares for comparisons between parental strains has been partitioned into three components, each with one

TABLE 3

Mean lengths of samples of ascospores from crosses between strains from ascus $23^{2}$

\begin{tabular}{|c|c|c|}
\hline Cross & $\begin{array}{c}\text { Mean length of samples } \\
\text { of twenty ascospores }\end{array}$ & Joint mean of samples \\
\hline $232-1$ & $17 \cdot 40$ & \\
$\times$ & $16 \cdot 85$ & \\
$232-3$ & $17 \cdot 30$ & \\
& $17 \cdot 50$ \\
$16 \cdot 25$ & \\
\hline & $17 \cdot 06$ \\
$232-1$ & $16 \cdot 40$ & \\
$\times$ & $17 \cdot 55$ & \\
$232-4$ & $18 \cdot 50$ & \\
& $17 \cdot 45$ & \\
\hline & $17 \cdot 61$ \\
$232-2$ & $17 \cdot 95$ & \\
$\times$ & $17 \cdot 65$ & \\
$232-3$ & $18 \cdot 00$ & \\
& $16 \cdot 95$ & \\
\hline & $17 \cdot 33$ \\
$232-2$ & $16 \cdot 50$ & \\
$\times$ & $17 \cdot 45$ & \\
$232-4$ & $18 \cdot 35$ & \\
& $19 \cdot 85$ & \\
\hline
\end{tabular}

degree of freedom, but none of these gives a significant variance ratio. That is, there is no difference between any of the twenty crosses which can be attributed to the parental strains. Although precautions were taken to minimise variation due to environmental causes, any difference between crosses which may have been due to different parental genotypes was small by comparison with the variation between replicate crosses.

A similar experiment was made with strains from the eight-spored ascus 234 and in this experiment, also, the differences between crosses with different parents were no greater than the differences between replicate crosses. In view of these experiments with sets of replicated crosses, it seems that the apparently significant differences previously described may have been due to the greatly increased variance in crosses between strains from the sixteenth generation of selection. 
This does not of course apply to the data from the backcrosses, which provide unequivocal evidence of segregation of polygenes.

\section{RECIPROCAL CROSSES}

A number of reciprocal crosses between strains derived from large ascospores from the fifteenth and sixteenth generations of selection, and stock wild-types were set up. It was observed that there were small but significant differences in the mean ascospore lengths of samples of ascospores from reciprocal crosses. In every case the mean ascospore length was greater when the wild-type strain was used as

TABLE 4

Analysis of variance of ascospore length in crosses between the four strains from ascus 232

\begin{tabular}{|c|c|c|c|c|}
\hline Item & $n$ & Mean square & $\mathrm{F}$ & Probability \\
\hline 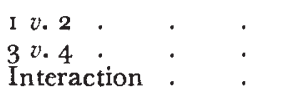 & $\begin{array}{l}1 \\
1 \\
1\end{array}$ & $\begin{array}{c}4 \cdot 40^{*} \\
24 \cdot 01 \\
0 \cdot 37^{*}\end{array}$ & $\begin{array}{c}2 \cdot 6648 \\
\ldots\end{array}$ & $\begin{array}{l}\cdots \\
>0 \cdot I \\
\cdots\end{array}$ \\
\hline $\begin{array}{l}\text { Total between strains } \\
\text { Between replicates }\end{array}$ & $\begin{array}{r}3 \\
16\end{array}$ & $\begin{array}{r}9 \cdot 593 \\
17 \cdot 255\end{array}$ & $\begin{array}{l}I \cdot 0647 \\
I \cdot 9150\end{array}$ & $\begin{array}{l}>0.2 \\
<0.05\end{array}$ \\
\hline Total between crosses & I9 & $16 \cdot 045$ & $1 \cdot 7807$ & $<0.05$ \\
\hline Error & $3^{80}$ & 9.010 & & \\
\hline Total & 399 & & & \\
\hline
\end{tabular}

* Not significantly smaller than error mean square.

the maternal parent, than in the reciprocal cross. The mean ascospore lengths of samples of Ioo ascospores from six different sets of reciprocal crosses are given in table 5, these include the four sets of reciprocal crosses made between the strains from the four large ascospores of ascus 233 and stock wild-types.

In addition, four different sets of reciprocal crosses between wildtype strains and strains derived from four of the normal-sized ascospores derived from ascus 234 are given in table 5. It can be seen from table 5 that there is no indication of any difference in the reciprocal crosses when strains derived from ascospores of normal size are crossed with wild-types. Yet ascus 234 was obtained from a cross between two large ascospores from the fifteenth generation of selection. In fact, ascus 233, which contained four large ascospores, and ascus 234 which contained eight ascospores of normal size (see table I) were both from the same perithecium. There was a difference between reciprocal crosses only when a strain derived from a phenotypically-large ascospore was crossed with a wild-type strain. An analysis of variance 
of the results obtained from the six sets of reciprocal crosses of largespored strains given in table 5 shows that the reciprocal difference is significant ( $\mathrm{F}=45 \cdot 25, \mathrm{P}$ c. OOI).

A further experiment was made with five replicates of each of the reciprocal crosses between the four strains from ascus 233 and the wild types StL. $A$ and I Ig6a. The total of forty crosses was set up in the most uniform fashion possible, in order to minimise environmental variation. A sample of twenty ascospores from each cross was measured and the results are given in table 6 . The analysis of variance of the results is given in table 7 .

It can be seen from table 7 that the difference between reciprocal crosses is significant. The mean square for the individual or residual

TABLE 5

Size of ascospores obtained from reciprocal crosses

\begin{tabular}{|c|c|c|c|}
\hline Cross & $\begin{array}{l}\text { Mean length of } \\
\text { samples of } \mathrm{I} \text { oo } \\
\text { ascospores }\end{array}$ & Cross & $\begin{array}{l}\text { Mean length of } \\
\text { samples of Ioo } \\
\text { ascospores }\end{array}$ \\
\hline $\begin{array}{l}\text { 1 } 077 \times \text { StL. } \\
\text { I } 078 \times \text { StL. } \\
233-\text { I } \times \text { I } 196 \\
233-2 \times \text { I } 196 \\
233-3 \times \text { StL. } \\
233-4 \times \text { StL. }\end{array}$ & $\begin{array}{l}\text { I } 2.95 \\
\text { I } 3.00 \\
\text { I } 3.22 \\
\text { I } 3.18 \\
\text { I } 3.56 \\
\text { I } 3.11\end{array}$ & $\begin{array}{l}\text { StL. } \times 1077 \\
\text { StL. } \times \text { 1078 } \\
\text { I I } 6 \times 233^{-1} \\
\text { I } 96 \times 233^{-2} \\
\text { StL. } \times 233-3 \\
\text { StL. } \times 233-4\end{array}$ & $\begin{array}{l}\text { I } 3.45 \\
\text { I } 3.39 \\
\text { I } 3.59 \\
\text { 1 } 3.92 \\
\text { I } 3.83 \\
\text { I } 3.5 \text { I }\end{array}$ \\
\hline $\begin{array}{l}234^{-1} \times \text { StL } . \\
234^{-2} \times \text { StL } \\
234-3 \times \text { StL } \\
234-4 \times \text { StL }\end{array}$ & $\begin{array}{l}\text { I } 3 \cdot 2 \text { I } \\
\text { I } 3 \cdot \text { I } 8 \\
\text { I } 3 \cdot 3^{8} \\
\text { I } 3 \cdot 3^{0}\end{array}$ & $\begin{array}{l}\text { StL. } \times 234-\mathrm{I} \\
\text { StL. } \times 234-2 \\
\text { StL. } \times 234-3 \\
\text { StL. } \times 234-4\end{array}$ & $\begin{array}{l}\text { I } 3.43 \\
\text { I } 3.0 \text { I } \\
\text { I } 3.29 \\
\text { I } 3.40\end{array}$ \\
\hline
\end{tabular}

Strains 1077 , I078, 233-1, 233-2, 233-3 and 233-4 are derived from large ascospores.

Strains I 96 and StL. are stock wild types.

Strains 234-I, 234-2, 234-3 and 234-4 are derived from normal-sized ascospores obtained from a cross between two strains from the fifteenth generation of selection.

variation is used as the denominator in the computation of $\mathrm{F}$ for the reciprocal effect, since it is larger than the mean square for the variation between replicate crosses.

The parental-genotype $\times$ reciprocal-difference interaction was also significant. The seven degrees of freedom for the eight sets of five replicate crosses may be partitioned individually. One of the three degrees of freedom for differences between parental genotypes may be used for the strain 233-I versus strains 232-2, 233-3 and 233-4 comparison. The interaction of this comparison with the reciprocal effect gives a sum of squares of $5 \cdot 7$ out of the total of $7 \cdot 18$ for the whole parental-genotypes $\times$ reciprocal-difference interaction. The value of $\mathrm{F}$ for this degree of freedom is $9.9, \mathrm{P} c$. oor. In other words, there is a significant interaction between strain $233^{-I}$ and the reciprocal difference, but no significant interaction between any of the other 
three strains from ascus 233 and the reciprocal effect. The reason for this is unknown.

It was necessary to use two wild-type strains of different mating types in the experiment. Strain I $96 a$ was derived from seven generations of backcrossing to StL. $A$, so the two strains should have been largely isogenic. In fact, the sum of squares for the comparison between the two wild-type parents was $0.1, M S=0.1, F=5.85, P>0.2$.

TABLE 6

Mean length of ascospores from replicate reciprocal crosses

\begin{tabular}{|c|c|c|c|c|c|}
\hline Cross & $\begin{array}{l}\text { Mean length of } \\
\text { samples of } 20 \\
\text { ascospores }\end{array}$ & $\begin{array}{l}\text { Joint } \\
\text { mean of } \\
\text { samples }\end{array}$ & Cross & $\begin{array}{l}\text { Mean length of } \\
\text { samples of } 20 \\
\text { ascospores }\end{array}$ & $\begin{array}{l}\text { Joint } \\
\text { mean of } \\
\text { samples }\end{array}$ \\
\hline $233^{-1} \times 1196$ & $\begin{array}{l}12 \cdot 95 \\
13 \cdot 00 \\
12 \cdot 80 \\
13 \cdot 00 \\
13 \cdot 15\end{array}$ & I $2 \cdot 98$ & I $196 \times 233^{-1}$ & $\begin{array}{l}\text { I } 3.60 \\
\text { I } 3.60 \\
\text { I } 3.65 \\
\text { I } 3.60 \\
\text { I } 3.80\end{array}$ & 13.65 \\
\hline $233^{-2} \times 1196$ & $\begin{array}{l}12 \cdot 80 \\
13 \cdot 00 \\
13.10 \\
13.30 \\
13.05\end{array}$ & 13.05 & I $196 \times 233-2$ & $\begin{array}{l}\text { I } 3.25 \\
\text { I } 3.45 \\
\text { I } 3.35 \\
\text { I } 3.65 \\
\text { I } 3.50\end{array}$ & 13.44 \\
\hline $233-3 \times$ StL & $\begin{array}{l}13.30 \\
13.35 \\
13.10 \\
13.15 \\
13.35\end{array}$ & 13.25 & StL. $\times 233-3$ & $\begin{array}{l}13.45 \\
13.25 \\
13.70 \\
13.35 \\
13.25\end{array}$ & 13.40 \\
\hline $233-4 \times$ StL & $\begin{array}{l}13 \cdot 15 \\
13 \cdot 15 \\
13 \cdot 25 \\
13 \cdot 10 \\
13 \cdot 00\end{array}$ & 13.13 & StL. $\times 233-4$ & $\begin{array}{l}\text { I } 3.50 \\
\text { I } 3.30 \\
\text { I } 3.50 \\
\text { I } 3.40 \\
\text { I } 3.45\end{array}$ & 13.43 \\
\hline
\end{tabular}

That is, there was no significant effect which could be attributed to the wild-type parental strains.

\section{DISCUSSION}

The increased range of ascospore size found in the backcross progeny compared with the $F_{1}$ indicates that a considerable number of genes differentiate the wild-types and the strains obtained after fifteen to sixteen generations of selection for increased ascospore size. This fact, together with the steady response to selection, suggests that a system of polygenes, which controlled to a considerable extent the number and size of ascospores in the asci, had been built up as a result of the selection.

Although it was not possible to estimate them independently, it is clear that there were three main results of selection : an increase 
in the average size of all ascospores, the development of asci containing four large ascospores instead of eight normal-sized ascospores, and developmental instability reflected in an increasing proportion of aborted ascospores and asci. The three main effects cannot really be considered separately, since they are obviously components of an integral phenomenon, yet they are suggestive of three main levels at which selection may have been effective. It is plausible to suggest

TABLE 7

Analysis of variance of ascospore length in replicate reciprocal crosses between the four members of ascus 233

\begin{tabular}{|c|c|c|c|c|}
\hline Item & $n$ & Mean square & F & Probability \\
\hline $\begin{array}{l}\text { Second order interactions : } \\
\text { R.E. } \times\left(\begin{array}{ll}1 & v .2+3+4)\end{array}\right. \\
\text { R.E. } \times \text { (other comparisons) }\end{array}$ & $\begin{array}{l}\text { I } \\
2\end{array}$ & $\begin{array}{l}5 \cdot 70 \\
0 \cdot 74\end{array}$ & $\begin{array}{l}9 \cdot 9 \\
7 \cdot 7 * \\
\mathrm{I} \cdot 26\end{array}$ & $\begin{aligned}< & 0.01 \\
& 0.1-0.2 \\
> & 0.2\end{aligned}$ \\
\hline $\begin{array}{l}\text { Total interaction } \\
\text { Between large-spored parent strains } \\
\text { Reciprocal effect (R.E.) }\end{array}$ & $\begin{array}{l}3 \\
3 \\
1\end{array}$ & $\begin{array}{l}2 \cdot 39 \\
0 \cdot 26 \dagger \\
28 \cdot 50\end{array}$ & $\begin{array}{c}4 \cdot 061 \\
\cdots \\
48 \cdot 428 \\
\text { I I } \cdot 92 \ddagger\end{array}$ & $\begin{array}{l}<0.01 \\
\quad \ldots \\
<0.001 \\
<0.05\end{array}$ \\
\hline $\begin{array}{l}\text { Total between eight different types } \\
\text { of cross } \\
\text { Between replicate crosses }\end{array}$ & $\begin{array}{r}7 \\
32\end{array}$ & $\begin{array}{l}5.21 \\
0.3568 \S\end{array}$ & $\begin{array}{c}8 \cdot 853 \\
\ldots\end{array}$ & $\begin{array}{c}<0 \cdot 001 \\
\quad \ldots\end{array}$ \\
\hline Total between all crosses & 39 & $I \cdot 228$ & $2 \cdot 086$ & $<0.001$ \\
\hline Error & 760 & 0.5885 & & \\
\hline Total . . . & 799 & & & \\
\hline
\end{tabular}

* This variance ratio was calculated using the mean square $(0.74)$ for the rest of the second order interaction as the denominator.

$\dagger$ Not significantly smaller than the error mean square.

\$ This variance ratio was calculated using the total interaction mean square as denominator.

$\S$ Significantly smaller than the error mean square at the $\cdot 05$ level.

that the initial source of genetic variability in the fungus was a mutation, a rare recombination, or both, which primarily affected the developmental stability of ascospore and ascus development. Consequently, environmental variation, which would have no appreciable effect on the development of the normal wild-type, might occasionally be sufficient to push development over some threshold in cell metabolism which determined whether or not mitosis should follow meoisis in the ascus initial. In this way, in a small proportion of asci, spore walls might be delimited around the four meiotic, nuclear products, instead of the usual eight ascospore initials. The fact that the ascospores in 
this type of ascus were large, might be simply a result of there being more cytoplasm available for inclusion in four instead of eight ascospores. It is probably significant that in the initial generations of selection no asci with four mature, large, ascospores were observed, but only single large ascospores together with aborted ascospore initials in each four-spored ascus. It suggests that the genotypic control of the development of the four-spored type of ascus was not at first sufficiently stable to produce more than an occasional single, large mature ascospore.

As selection for phenotypically-large ascospores proceeded, three at least partially independent systems of modifying genes might be built up, if the genetic variance was available. One system would be responsible for an overall increase of ascospore size as such. Another might lower still further the threshold at which the switch from the eight-spored to the four-spored type occurs, with a resultant increase in the number of the four-spored type and in the number of aborted asci. A situation analogous to this has been discussed by Waddington (1953). The third system would be responsible for an increased stability of development in some of the four-spored asci with an increase in the number of mature, large ascospores. It has been demonstrated by Mather (1953) that developmental stability in Drosophila is under genetic control and can be affected by selection. All of these systems would contribute in some measure to the increase in frequency of phenotypically-large ascospores.

This explanation of the mode of operation of selection is, of course, only speculative. But there is one aspect of the response to selection which seems fairly clear. The "plateau" at about I8-I9 units, when after the previous rapid response the method of selection practised apparently became ineffective, was probably a result of the developmental instability which itself formed part of the response to selection. At this level the variation in ascospore size due to slight and uncontrollable environmental causes, was a good deal larger than that due to genotypic differences. Consequently the ascospore phenotype no longer provided a sufficient indication of the ascospore genotype for the method of selection to be effective in promoting a further increase of size. This kind of situation in Drosophila has been discussed by Thoday (I 955).

The difference between reciprocal crosses of cultures from phenotypically-large ascospores and wild-type strains, is interesting for two reasons. First, because it is the cross with the wild-type as the maternal parent which gives the greater mean ascospore length in the progeny and not the other way about. Second, there was no reciprocal effect in crosses with wild-types of cultures from phenotypically normalsized ascospores, such as those of ascus 234, which are derived from large-spored strains produced by fifteen to sixteen generations of selection. Yet, crosses between cultures from these phenotypically normal-sized ascospores, see table 4 , show that their genotypes are 
very similar to those of the phenotypically-large ascospores. Present information does not suggest any obvious explanation of this reciprocal effect. It is obvious that the difference between reciprocal crosses is closely connected with the control of ascus development. It remains to be discovered at which stage in development, and in what way, the number and size of the ascospores to be delimited in the ascus is determined. If this were known it would probably provide an explanation of the reciprocal difference. Alternatively, it may be that further experimental investigation of the reciprocal effect will increase our understanding of ascus development.

In addition to three species with eight-spored asci like Neurospora crassa, the genus Neurospora contains three species, such as Neurospora tetrasperma, which have four-spored asci. It is usually considered that the four-spored species of Neurospora are derived from the eightspored forms (Dodge et al., 1950). When postulating the evolution of a species with four large ascospores per ascus from one with eight smaller ascospores per ascus, it is not easy to suggest any selective advantage which might result in such an evolution. But the progress of the selection experiment can be used to suggest one way in which the four-spored forms may have evolved from one or more of the eightspored species.

It may be that the initial stage of divergence from an ancestral eight-spored form was not directly connected with ascospore size or number of ascospores per ascus at all. If some change in the environment occurred which exceeded the range of conditions to which the ancestral eight-spored species was well adapted, this might confer a selective advantage upon a genetic variant which possessed greater adaptability in some way at the biochemical level in cell development. The altered physiological conditions in the cells of the better adapted genetic variant growing in the different environment might indirectly result in a switch from the eight-spored to the four-spored type of ascus development. If such a switch occurred in a significant proportion of asci it might well have the following consequences. At first a large number of asci would probably abort at various stages, since the new type of ascus is not likely to have been initially as stable in development as the ancestral eight-spored type of ascus perfected by a long period of natural selection. This ascus abortion, together with reduction of the number of ascospores per ascus by a half without a corresponding doubling of the number of asci would cause a marked decrease in the number of viable ascospores. This reduction would confer a selective advantage on any modifying genes which increased the proportion of viable ascospores in the four-spored type of ascus. The production of homothallic ascospores might also have had a selective advantage in a species where the number of ascospores was limiting. Thus a species regularly producing four self-fertile ascospores per ascus may have come into being. This explanation of how a four-spored species may have evolved is obviously derived in many 
respects from the way in which the selection experiment is known to have proceeded. There are also several further points which ought to be mentioned in this connection.

The gene E, reported by Dodge et al. (I950) in Neurospora tetrasperma, affects some vital step in the metabolism of the ascus initial, since it behaves as a dominant lethal resulting in the abortion of practically all the asci when a strain carrying it is mated on the usual media. But on a special potato steep medium the asci of this type of cross do not abort, instead they delimit eight small ascospores. This mutant strain illustrates the fact that some biochemical step in the cell can determine the type of ascus development, and that this metabolic step is at least partially controlled by the gene $\mathrm{E}$. It will be remembered that the hypothesis outlined above suggests that an adaptive physiological change, made possible by genotypic variation, was the prime cause of evolutionary divergence, while the morphological changes were an indirect result.

The work of Dodge (1928) shows that the inheritance of the fourspored and eight-spored types of ascus in crosses and backcrosses between $\mathcal{N}$ eurospora sitophila and $\mathcal{N}$ eurospora tetrasperma is at least partly polygenic. The existence of these polygenic differences between an eight-spored and a four-spored species increases the plausibility of the suggestion that the build-up of some such system of modifying genes comprised part of the second stage of the evolution of the four-spored species.

It is improbable that the origin of such four-spored species as Neurospora tetrasperma will ever be known with certainty. But at least a hypothesis can be proposed which is in accord with what is at present known, from three independent pieces of experimental work, about the relevant genetic nature of $\mathcal{N}$ eurospora species.

\section{SUMMARY}

(I) Selection for increased ascospore size in Neurospora crassa for sixteen generations had the following main results :

(a) The mean ascospore size increased from about $27 \mu \times \mathrm{I}_{5} \mu$ to about $37 \mu \times \mathrm{I} 8 \mu$.

(b) The eight-spored type of ascus characteristic of wild-type Neurospora crassa became very rare, and asci containing four large ascospores were produced by crosses between the selected strains. Strains from the sixteenth generation of selection produced about one ascus with four large, apparently mature ascospores in every three perithecia.

(c) There was a great increase in the frequency of aborted asci and ascospores. In crosses between strains from the sixteenth generation of selection, only about 20 per cent. of the asci contained mature ascospores.

(d) The method of selection practised became ineffective after about eight generations, and there was no significant 
The effects of selection for large ascospore size in Neurospora crassa.

FIG, I.-The $F_{1}$ asci from a cross between the large-spored strain 233-2 and a wild-type I 196 . All the asci contain eight normal-sized spores and are indistinguishable from those produced by a wild-type $\times$ wild-type cross. $\times 45$.

Fig. 2.-Part of the contents of a perithecium from a cross between the two large-spored strains 233-2 and 233-4: both strains came from the sixteenth generation of selection. There are several of the four-spored type of ascus, each containing one, two or three mature large spores. There is one ascus which contains eight normal-sized spores, but none of these are mature. $\times 50$.

Fig. 3.-Part of the contents of a perithecium from a cross between the two normal-spored strains $234-3$ and $234-7$, both strains came from the sixteenth generation of selection. This shows the close similarity to the type of cross illustrated in fig. $2 . \times 50$.

Fig. 4.-The four-spored ascus is from the backcross of an $F_{1}$ strain, 1238 , to the largespored parental strain, $233-4$. The sizes of the spores are $2 \mathrm{I} \times 8,23 \times 8,20 \times 8$ and $20 \times 8$. $\times 280$.

FIG. 5.-The five-spored ascus is from the same backcross as in fig. 4. The sizes of the spores are $16 \times 8,16 \times 8$, I $5 \times 7,12 \times 7$ and $13 \times 7 . \times 300$.

FIG. 6. - The eight-spored ascus is from the same backcross as figs. 4 and 5. It is typical of the majority of complete asci in the backcross. The sizes of the spores are $14 \times 7,14 \times 7$, $\mathrm{I} 3 \times 7, \mathrm{I} 2 \times 7, \mathrm{I} 4 \times 7, \mathrm{I} 4 \times 7$ and $\mathrm{I} 3 \times 6 . \times 225$. 


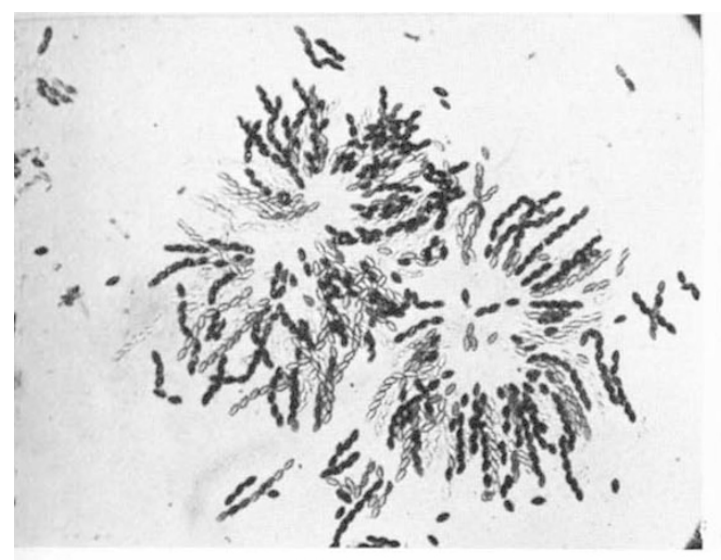

Frg. I

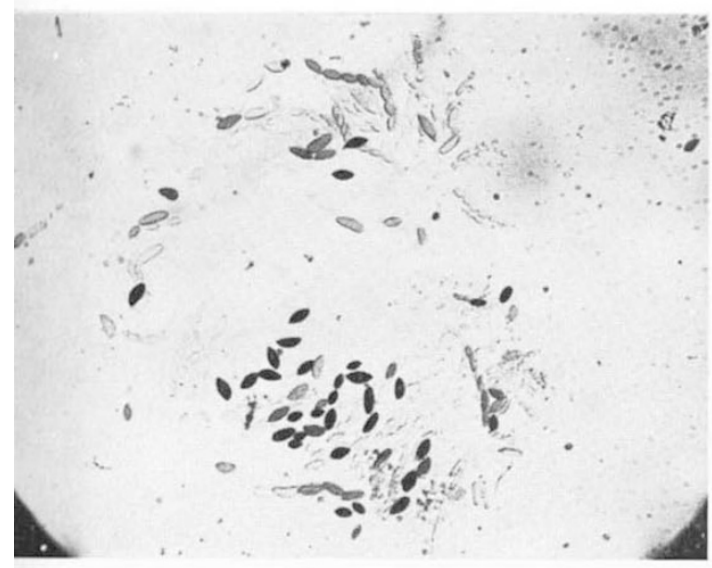

FIG. 3

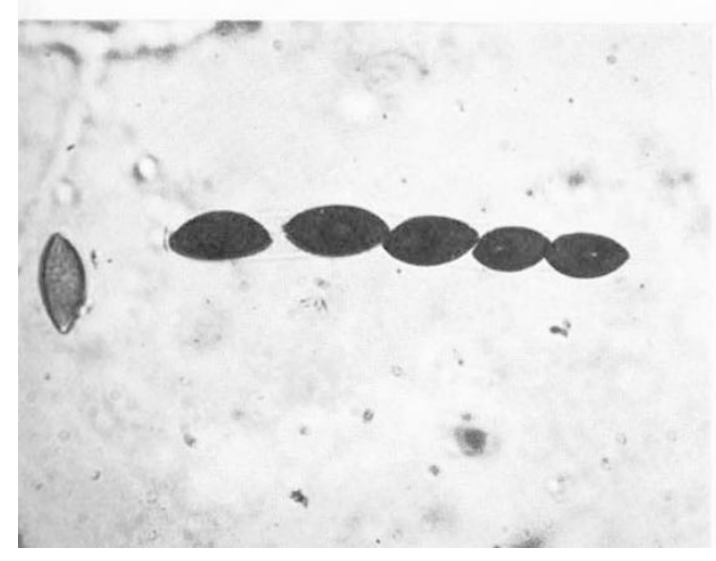

FIG. 5

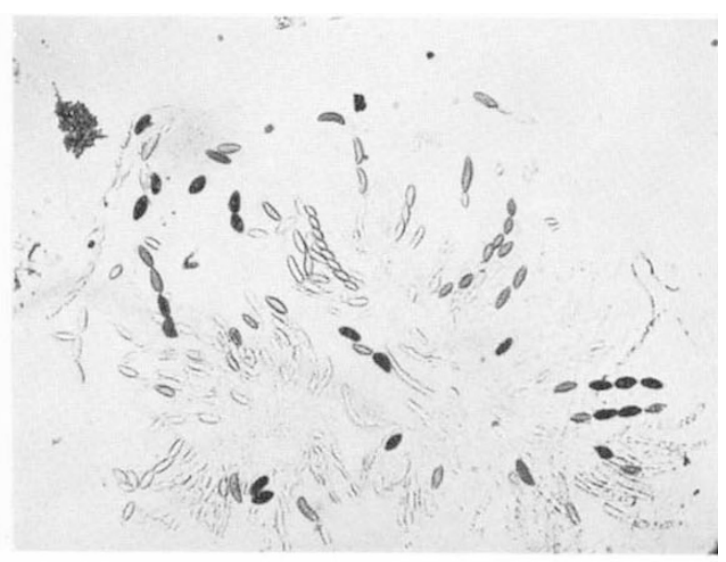

Fig. 2

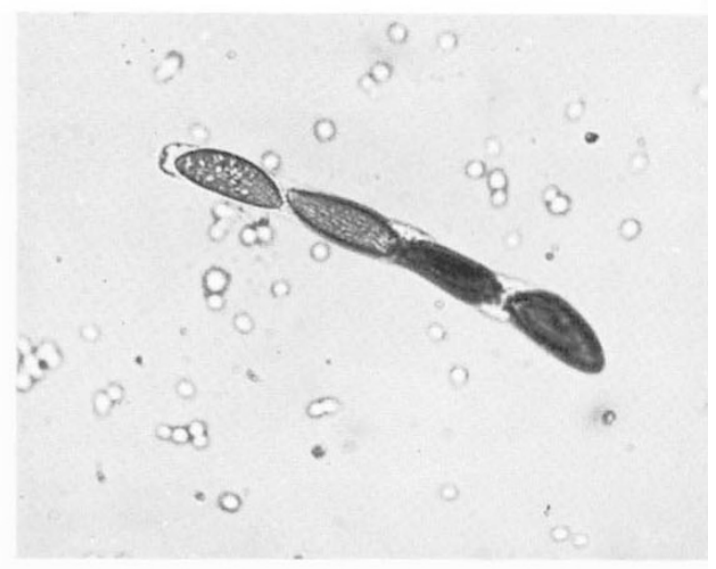

FIG. 4

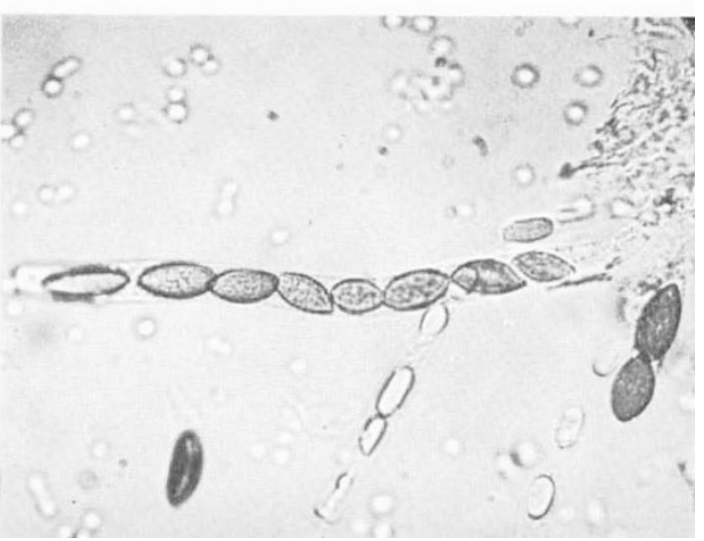

FIG. 6 
deviation from the level reached in the eighth generation during the succeeding ninth to sixteenth generations of selection.

(2) In crosses between wild-type strains and large-spored strains obtained after selection, the $F_{1}$ asci all contained eight normal ascospores and were indistinguishable from those produced by wild-type crosses. There was no indication of unusual ascus or ascospore abortion in $\mathbf{F}_{\mathbf{1}}$ progeny. Thus the wild-type genotype showed complete dominance.

(3) It is considered that the inheritance of ascospore size and type of ascus development in Neurospora crassa is chiefly controlled by a system of polygenes for the following three reasons. The mean ascospore size steadily increased for eight generations in response to selection. There was considerable variation in individual ascospore size in the progeny from crosses between large-spored strains. There was a wide range of mean ascospore sizes in twenty-eight different backcrosses to a large-spored parent strain.

(4) There was a significant difference between reciprocal crosses of large ascospore strains from the sixteenth generation of selection with wild-type strains. When the wild-type strain was the maternal parent the mean length of the $F_{1}$ ascospores was about I $\mu$ greater than the mean length of the $F_{1}$ ascospores from the reciprocal cross.

A hypothesis is proposed to account for the results observed in the selection experiment. An explanation is also suggested of one way in which selection may have resulted in the evolution of the four-spored species of Neurospora from one or more ancestral eight-spored species.

Acknowledgment.-I am indebted in this work to the Agricultural Research Council for some technical assistance, which was made possible by a grant made by them to Dr J. M. Thoday.

\section{REFERENCES}

BEADLE, G. W., AND TATUM, E. L. 1945. Methods of producing and detecting mutations concerned with nutritional requirements. Amer. F. Bot., 32, 678-686.

DODGE, B. о. 1928. Production of fertile hybrids in the ascomycete Neurospora. J. Agric. Research, 36, I-14.

DODGE, B. O., singleton, J. R., AND Rolnick, A. I950. Studies on lethal E gene in Neurospora tetrasperma, including chromosome counts also in races of Neurospora sitophila. . roc. Amer. \& hil. Soc., 94, I. 38-52.

GARNJOBST, L., AND wilson, J. F. I 956 . Heterocaryosis and protoplasmic incompatibility in Neurospora crassa. Proc. nat. Acad. Sci., Wash., 42, 61 3-61 8.

MATHER, K. I953. Genetical control of stability in development. Heredity, 7, 297-336.

Pateman, J. A. I955. Polygenic inheritance in Neurospora. Nature, Lond., I76, I $274^{-1} 275$.

THodAy, J. M. I955. Balance, heterozygosity and developmental stability. Cold Spr. Harb. Symp. quant. Biol., 20, 31 8-326.

WAdDington, C. H. I 953 . Genetic assimilation of an acquired character. Evolution, 7 , I I 8-I 26.

WEstergaARD, M., AND mitchell, H. K. 1947. Neurospora V. A synthetic medium favouring sexual reproduction. Amer. F. Bot., 34, 573-577. 